\title{
A Comparison of One Shape and ProTaper Next Rotary Systems for Elimination of Enterococcus Faecalis from Root Canal: Microbiological and SEM Evaluation
}

\author{
Renu Bala Sroa, Baljeet Sidhu, Sangeeta Aggarwal, Aakanksha Chopra, Angelina Bedi \\ Department of Conservative Dentistry and Endodontics, Punjab Government Dental College \& Hospital, Amritsar, India \\ Email address: \\ dr_sidhu2001@yahoo.com (B. Sidhu)

\section{To cite this article:} \\ Renu Bala Sroa, Baljeet Sidhu, Sangeeta Aggarwal, Aakanksha Chopra, Angelina Bedi, A Comparison of One Shape and ProTaper Next \\ Rotary Systems for Elimination of Enterococcus Faecalis From Root Canal: Microbiological and SEM Evaluation. American Journal of \\ Internal Medicine. Vol. 6, No. 5, 2018, pp. 126-131. doi: 10.11648/j.ajim.20180605.16
}

Received: June 13, 2018; Accepted: July 24, 2018; Published: September 17, 2018

\begin{abstract}
Incomplete removal of micro- organisms from infected root canals is a common cause of failed endodontic treatment. The difficulty in eradication of Enterococcus faecalis from root canals plays an essential role in pathogenesis of persistent pulpal and periradicular infections. The aim of the present study was to compare the reduction of Enterococcus faecalis in root canals by mechanical instrumentation using two rotary systems (One Shape and ProTaper Next) and Hand Kfile instrumentation by using microbiological and Scanning Electron Microscopy (SEM) evaluation. Fifty one freshly extracted mandibular premolars with a single root were collected. After pre- instrumentation sampling, they were divided into three groups, Group A, Group B and Group C in which biomechanical preparation was done using Hand K- File, OneShape and Protaper Next respectively. Reduction in pre- instrumentation and post- instrumentation values of Enterococcus faecalis were analysed using microbiological and SEM evaluation. Statistical analysis by paired ' $\mathrm{t}$ ' test and $\mathrm{p}$ value showed that there was highly statistical significant difference in CFU count reduction between the pre-instrumentation and post-instrumentation values in all the groups $(\mathrm{p}<0.001)$. Statistical analysis by Kruskal-Wallis Test and Mann-Whitney Test showed that at $1 \mathrm{~mm}$ and $3 \mathrm{~mm}$ level, Group A (Hand K-File) scored significantly higher value followed by Group B (OneShape Apical) and Group C (ProTaper Next). The most effective instrumentation technique in eliminating Enterococcus faecalis from the root canal was ProTaper Next system in comparison to OneShape Apical and Hand K-File.
\end{abstract}

Keywords: Enterococcus Faecalis, Hand K-File, OneShape Apical, ProTaper Next

\section{Introduction}

Micro-organisms play an essential role in pathogenesis of pulpal and periradicular diseases and are an important factor affecting the results of endodontic treatment. Therefore, endodontic treatment should be directed towards prevention of bacterial infection in the root canal or eradication of bacteria in the case of infected root canals.

Amongst the diverse bacteria species found in endodontic infections, Enterococcus faecalis stands out for its ability to grow in the presence or absence of oxygen, penetrate deep into dentinal tubules and survive adverse environmental conditions such as extreme alkaline $\mathrm{pH}$, high temperatures and scarce nutrition. Pinheiro S L et al [1] reported that Enterococcus faecalis is the most frequent species found in persistent endodontic infections with a prevalence of $90 \%$ and is nine times more likely to be isolated from root-filled teeth than from primary infections. Its inherent resistance to intracanal disinfecting agents, adaptability to the harsh environmental stresses and ability to form biofilms within the root canals makes it the primary organism associated with post-treatment failure and association with persistent apical periodontitis, which makes it focus of research.

Mechanical instrumentation is the core method for bacterial reduction during endodontic treatment of infected root canals. Bystrom A and Sundqvist G [2] demonstrated that mechanical instrumentation with a non-antimicrobial irrigant reduces the intracanal bacterial count enough to detect a quantifiable difference using appropriate sampling techniques. 
Although manual instrumentation is commonly used by practitioners, Foschi $\mathrm{F}$ et al [3] demonstrated that the latest nickel-titanium (Ni-Ti), variable taper, rotary instruments are a relatively new approach to obtain good root canal preparation with standardized taper, in less time than necessary for manual preparation. The single-file technique, for root canal instrumentation has been recently proposed mostly because of convenience and alleged simplification. Burklein S, Benten S, Schafer E [4] demonstrated that the preparation time is decreased by up to $60 \%$ by using singlefile system when compared with multiple-file system.

Fifth generation single file system, OneShape (Micromega, Besancon, France) is a new Ni-Ti single-file system used in continuous clockwise rotational motion for quick and safe root canal preparation. The file has three different crosssections along the file length that generates travelling waves of motion along the active part of the file and a $6 \%$ taper reduced the significant bacterial count including the quality root canal preparations. Mittal $\mathrm{R}$ et al [5] reported that OneShape extruded significantly lesser bacteria when compared with ProTaper system. However, OneShape tends to modify the canal curvature and original canal anatomy.

Recently introduced, ProTaper Next files (Dentsply Maillefer, Ballaigues, Switzerland) are manufactured by using $\mathrm{M}$-wire $\mathrm{Ni}$-Ti to enhance their flexibility and cyclic fatigue resistance. This system makes use of the multiple progressive taper concept on a single-file which allows for only small area of dentin to be engaged. In addition, these files exhibits an off-centered rectangular cross-section design that increases the strength, decreases the screw effect, taper lock and torque by minimizing the contact of files with the dentin. Chandrasekhar P et al [6] found acceptable cleaning ability of ProTaper Next at apical, middle and coronal thirds of root canals.

Few studies were performed on the mechanical reduction of intracanal bacteria by ProTaper Next and OneShape Apical. However, to date, there are no studies that evaluate both microbiologically and by scanning electron microscopic analysis, the ability of ProTaper Next system to remove intracanal bacteria and compare the results with those of OneShape Apical single-file system.

Therefore, the aim of present study was to compare the reduction of Enterococcus faecalis in root canals by mechanical instrumentation using two rotary systems (OneShape and ProTaper Next) and Hand K-file instrumentation by using microbiological and SEM evaluation.

\section{Method}

Fifty-one freshly extracted human permanent mandibular premolars with a single root were collected and were analyzed using radiography to confirm a single canal \& apical foramen and a non complicated root canal anatomy.

Teeth were initially stored in $10 \%$ formalin for 24 hours, to provide disinfection and organic tissue fixation. Then bone, calculus and soft tissues on the root surface were removed with curettes (Hu-Friedy, USA) without damaging the root surface. The tooth crown was decoronated to standardize the root length to $16 \mathrm{~mm}$, perpendicular to its long axis by using a diamond rotary disc mounted on mandrel (SS White, New Jersey) in straight handpiece (NSK, Japan) at 30, 000rpm. Patency of each canal was determined with \# $10 \mathrm{~K}$-file. The canal length was obtained by using K-file (Dentsply Maillefer, Ballaigues, Switzerland) until the tip of the file was visible at the apical foramen and the working length was established by subtracting $1 \mathrm{~mm}$ from the canal length. A Gates Glidden \#2 bur (Dentsply Maillefer, Ballaigues, Switzerland) was used to provide the enlargement from the coronal one-third of the canal. Root canals were instrumented to a size \#25 K-file. Irrigation was done with $2 \mathrm{ml}$ of saline solution (Parenteral Surgicals Ltd) using a $2.5 \mathrm{ml}$ plastic syringe with a 23-gauge needle (NIPRO Medical Corporation). The root canals were filled with $17 \%$ ethylene diamine tetraacetic acid (Dentsply International, New York, United States) for 3 min to remove the smear layer. All the canals were finally rinsed with $5 \mathrm{ml}$ of distilled water. To prevent bacterial leakage, the apical foramen was sealed with composite resin and the surfaces of all roots were varnished with nail polish. To make handling easier, the teeth were mounted vertically in acrylic resin.

Moisture was removed from the root canals with sterile paper points (Dentsply International, New York, United States) and the teeth were air dried for 8 hours before sterilization. Sterilization was accomplished by using an autoclave (Steriline, Dental X, Italy) at $121^{\circ} \mathrm{C}$ and $15 \mathrm{lb} / \mathrm{in}^{2}$ for 20 minutes. The roots were randomly divided into three groups viz: Group A, Group B and Group C with seventeen teeth in each group. One root from each group was selected randomly in order to confirm the sterilization, microbiologically as well as microscopically (Scanning Electron Microscopy).

The root canals of remaining forty-eight specimens were contaminated using a pure culture of Enterococcus faecalis (ATCC 29212). Colonies of E. faecalis, grown on brain heart infusion with $5 \%$ sheep blood agar plates incubated at $37^{\circ} \mathrm{C}$ for 48 hours in a $\mathrm{CO}_{2}$ incubator, were inoculated in $\mathrm{BHI}$ broth and left for 24 hours (McFarland standard no. 4 was used to evaluate the broth in order to ensure that the bacterial count was approximately $1.2 \times 10^{9}$ colony forming units per milliliter). Each root canal was completely filled with $20 \mu \mathrm{L}$ of E. faecalis suspension through their cervical apertures using sterile micropipettes. The cervical access was sealed with temporary cement (MD-Temp, Meta Biomed Co Ltd). The blocks were then placed inside sterile plastic bags and were incubated at $37^{\circ} \mathrm{C}$ for 24 hours. To confirm the contamination by $\mathrm{E}$. faecalis, three roots (one from each group) were selected randomly and analysed by scanning electron microscopy.

Initial samples were collected from contaminated remaining specimens using sterilized \#15 paper points (Dentsply International, New York, United States) in each group $(n=15)$. The paper points were inserted into the canals for 1 minute and stored in tubes containing $500 \mathrm{ml}$ peptone 
water. Serial dilutions were prepared and were plated in brain heart infusion agar. The plates were incubated at $37^{\circ} \mathrm{C}$ for 24hours for bacterial count in colony-forming units (CFUs)/ml.

After pre-instrumentation sampling, roots in Group A, Group B and Group C were prepared by Hand K-file, OneShape and ProTaper Next, respectively.

\section{GROUP A (Hand K-file)}

The root canals were prepared by using the crown-down manual technique. The cervical and middle third was enlarged with Gates-Glidden drills \#1, \#2 and \#3 and the root canals were instrumented at the working length using quarter turn and filing movements against the walls, up to a \#30 Kfile. This movement was repeated until the instrument no longer met resistance, and the file was free.

\section{GROUP B (OneShape)}

The root canals were prepared by using OneShape system (0.25/0.06) (Micromega, Besancon, France) with a motor (Nsk Japan) in continuous rotation motion at $400 \mathrm{rpm}$ and a torque of $2.5 \mathrm{~N}$. cm. Three in-and-out motions were gently performed in the apical direction. Then, the root canal was explored up to the working length using \#15 K-file. This kinematics was performed until reaching the full working length. Apical finishing was done with OneShape Apical 1 (0.30/0.06) (Micromega, Besancon, France) at $400 \mathrm{rpm}$ and a torque of $1 \mathrm{~N} . \mathrm{cm}$.

\section{GROUP C (ProTaper Next)}

Biomechanical preparation was done by using ProTaper Next (Dentsply Maillefer, Ballagigues, Switzerland) files in the sequence of ProTaper Next X1(0.17/0.04), X2 $(0.25 / 0.06), \mathrm{X} 3(0.30 / 0.075)$ at a rotational speed of $300 \mathrm{rpm}$ and $2 \mathrm{~N}$. cm torque. Varghese $\mathrm{N} \mathrm{O}$ et al [7] evaluated the resistance to torsional failure and cyclic fatigue resistance of ProTaper Next (PTN), WaveOne (WO), and Mtwo (MT) files in continuous and reciprocating motion. Each file was used with a brushing motion

Irrigation was delivered in the canals by means of a $5 \mathrm{ml}$ disposable syringe with a 23-gauge needle by using $10 \mathrm{ml}$ sterile saline between the files in each group

Bacterial samples were acquired with \#25 paper points. The paper points were placed into the canal and kept there for about $1 \mathrm{~min}$. Hartroth B, Seyfahrt I, Conrads G [8] reported that a sampling time of 60 seconds is optimum compared with shorter times between 5 and 30 seconds.

The points were then transferred into tubes containing 500 $\mathrm{ml}$ peptone water and serial dilutions were prepared. Different dilutions were plated in brain heart infusion agar and plates were incubated at $37^{\circ} \mathrm{C}$ for 24 hours for bacterial count in colony-forming units (CFUs)/ml. (Figure 1, Figure 2, Figure 3)

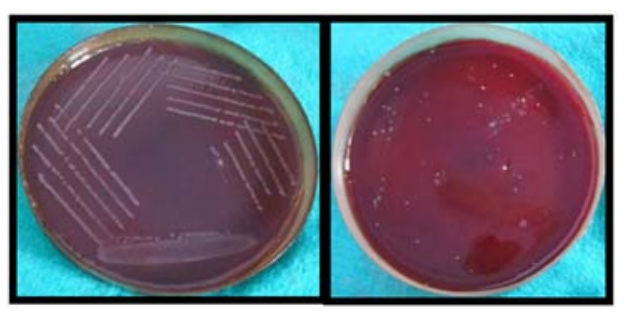

Figure 1. Culture Plates Showing Pre and Post-Instrumentation Colonies In Group A (Hand K-File).

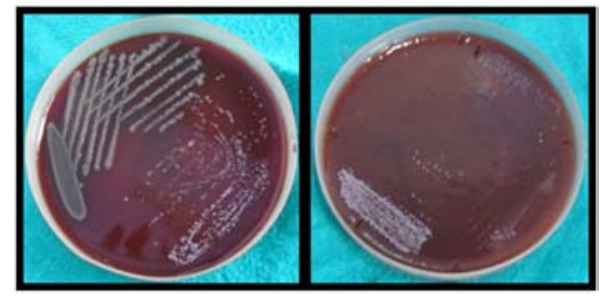

Figure 2. Culture Plates Showing Pre and Post-Instrumentation Colonies In Group B (OneShape).

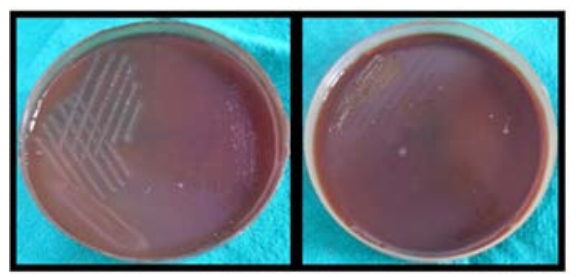

Figure 3. Culture Plates Showing Pre and Post-Instrumentation Colonies In Group C (ProTaper Next).

Two Longitudinal grooves were prepared in the buccal and lingual aspects of the roots without perforating the root canals to split them into two halves using mallet and chisel. One half of each root was selected for examination under a scanning electron. Then the root halves were dehydrated in ascending concentration of ethanol i. e. $50 \%$ for $5 \mathrm{mins}, 70 \%$ for $5 \mathrm{~min}, 80 \%$ for $5 \mathrm{~min}$, and $100 \%$ for $30 \mathrm{~min}$. The specimens were dried in a critical point dryer. The roots were mounted on metallic stubs, gold sputtered and examined under Scanning Electron Microscope (SUPRA 55VP, ZEISS, Germany). The images were taken at $1 \mathrm{~mm}$ and $3 \mathrm{~mm}$ from the apical foramen. (Figure 4, Figure 5, Figure 6, Figure 7, Figure 8, Figure 9)

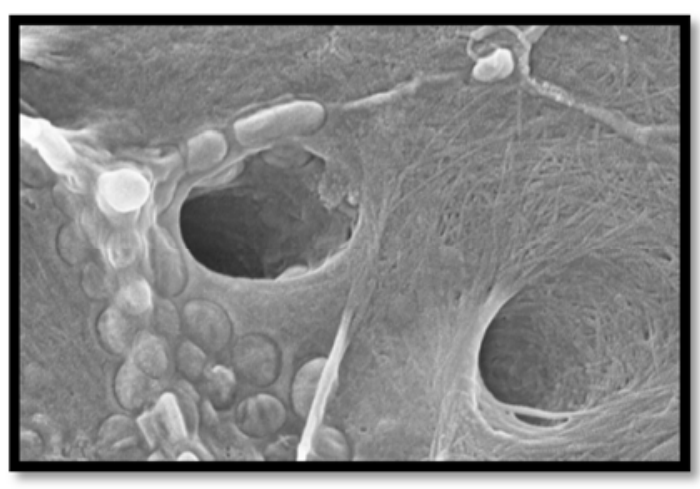

Figure 4. SEM Score 3, at $1 \mathrm{~mm}$ Level In Group A (Hand K-file). 


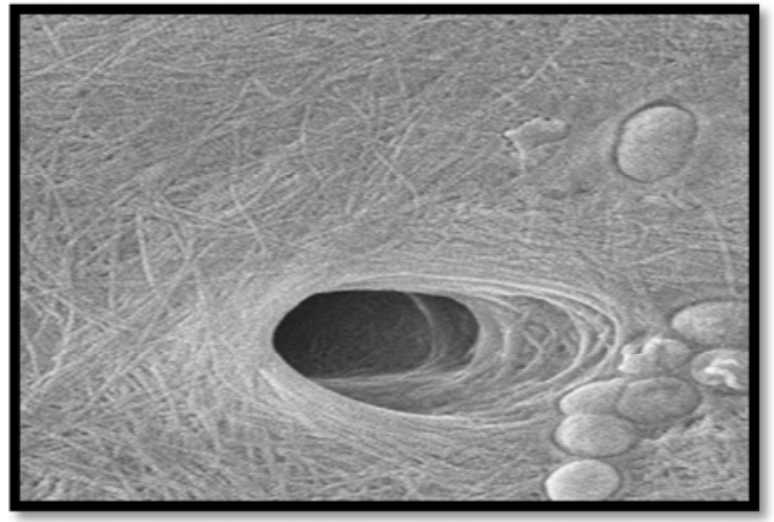

Figure 5. SEM Score 2, at 3mm Level In Group A (Hand K-File).

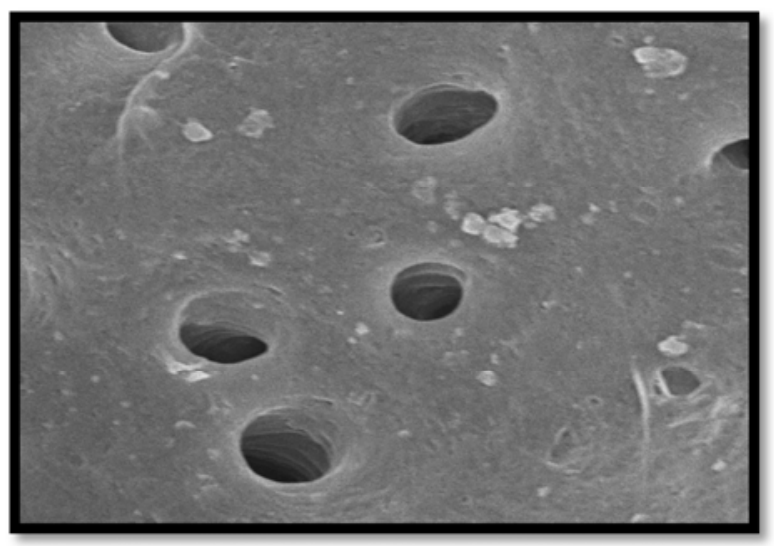

Figure 6. SEM Score 2, at 1mm Level In Group B (One Shape).

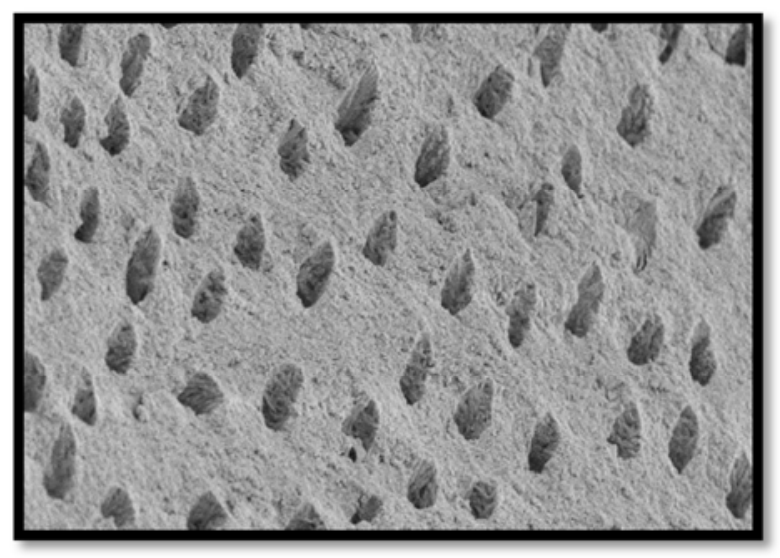

Figure 7. SEM Score 1, at 3mm Level In GROUP B (One Shape).

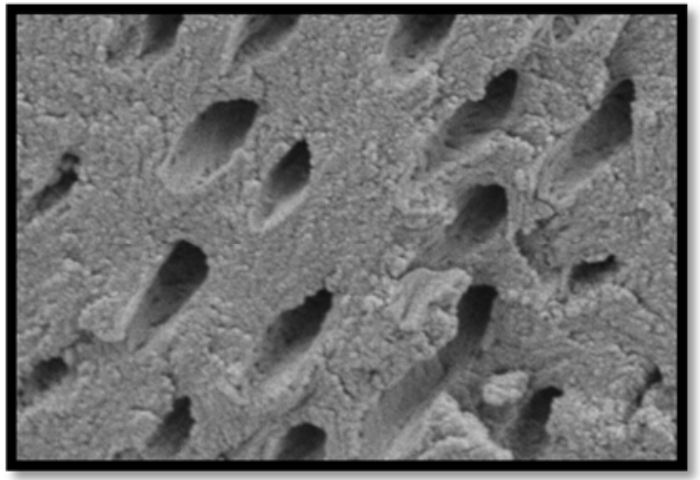

Figure 8. SEM Score 1, at 1mm Level In Group C (Pro Taper Next).

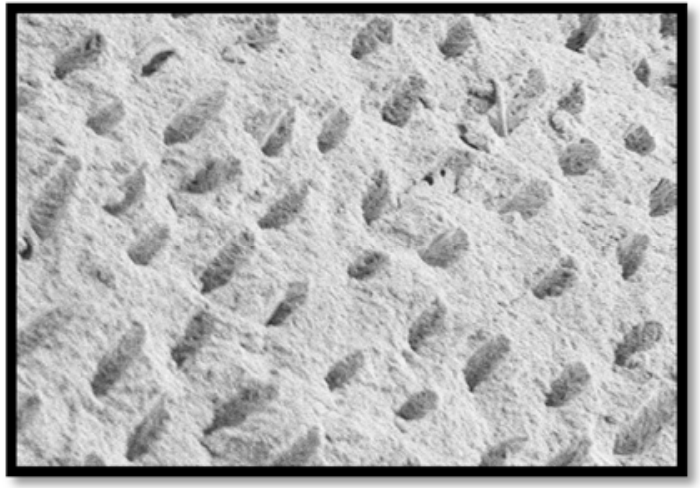

Figure 9. SEM Score 1, at 3mm Level In Group C (Pro Taper Next).

Scoring for bacteria was performed according to the scoring criteria, Paranjpe A et al [9]:

No bacteria on the surface of the root canal

Isolated bacteria over the surface with no signs of viability/organization (mitosis, biofilm matrix)

Agglomeration of bacteria with signs of viability/organization (mitosis, biofilm matrix)

More than $50 \%$ of the root canal wall covered with viable bacteria

Complete or nearly complete root canal wall coverage with viable bacteria

Attributed data were tabulated and statistically evaluated using Paired ' $\mathrm{t}$ ' test, One Way ANOVA with Post HOC comparison using Tukey test for microbiological evaluation and Kruskal-Wallis and Mann-Whitney Test for scanning electron microscopic evaluation.

\section{Results}

Table 1. Mean Reduction In Pre-Instrumentation and Post-Instrumentation Values Using Paired 't' Test.

\begin{tabular}{|c|c|c|c|c|c|c|}
\hline \multirow{2}{*}{ Group } & \multicolumn{2}{|l|}{ S1 } & \multicolumn{2}{|l|}{ S2 } & \multirow{2}{*}{$\begin{array}{l}\text { Reduction } \\
\text { from S1 to } S 2\end{array}$} & \multirow{2}{*}{ p value ${ }^{\#}$} \\
\hline & Mean & SD & Mean & SD & & \\
\hline Group A & $8.3 \times 10^{4}$ & $3.03 \times 10^{4}$ & $0.37 \times 10^{4}$ & $0.13 \times 10^{4}$ & $7.93 \pm 2.93$ & $<0.001 * *$ \\
\hline Group B & $9.8 \times 10^{4}$ & $3.16 \times 10^{4}$ & $0.23 \times 10^{4}$ & $0.11 \times 10^{4}$ & $9.65 \pm 3.07$ & $<0.001 * *$ \\
\hline Group C & $7.6 \times 10^{4}$ & $3.15 \times 10^{4}$ & $0.15 \times 10^{4}$ & $0.10 \times 10^{4}$ & $7.53 \pm 3.07$ & $<0.001 * *$ \\
\hline
\end{tabular}

\#Paired ' $\mathrm{t}$ ' test; ${ }^{* *} \mathrm{p}<0.001$; Highly significant; SD- standard deviation

As per the table I, statistical analysis by paired ' $t$ ' test and $p$ value showed that there was highly statistical significant 
difference in CFU count reduction between the pre-instrumentation and post-instrumentation values in all the groups $(\mathrm{p}<0.001)$.

Table 2. Mean of SEM Scores at $1 \mathrm{~mm}$ and at $3 \mathrm{~mm}$ Level Using Kruskal-Wallis and Mann-Whitney Test.

\begin{tabular}{|c|c|c|c|c|}
\hline \multirow{2}{*}{ Group } & \multicolumn{2}{|l|}{ Score at $1 \mathrm{~mm}$} & \multicolumn{2}{|c|}{ Score at $3 \mathrm{~mm}$} \\
\hline & Mean \pm SD & P value ${ }^{\mathrm{S}}$ & Mean \pm SD & p value $^{\mathrm{s}}$ \\
\hline Group A & $2.47 \pm 0.64$ & & $1.93 \pm 0.46$ & \\
\hline Group B & $1.87 \pm 0.74$ & $0.001 *$ & $1.47 \pm 0.52$ & $0.003^{*}$ \\
\hline Group C & $1.40 \pm 0.63$ & & $1.27 \pm 0.46$ & \\
\hline
\end{tabular}

\$Kruskal-Wallis Test; \#Mann-Whitney Test; NS: $\mathrm{p}>0.05$; Not significant; ${ }^{*} \mathrm{p}<0.05$; Significant

As per table 2, statistical analysis by Kruskal-Wallis Test and Mann-Whitney Test showed that at $1 \mathrm{~mm}$ and $3 \mathrm{~mm}$ level, Group A (Hand K-File) scored significantly higher value followed by Group B (OneShape Apical) and Group C (ProTaper Next).

\section{Discussion}

The present study was designed to compare OneShape and ProTaper Next rotary file systems for elimination of Enterococcus faecalis from root canal by using microbiological and SEM evaluation.

Freshly-extracted human teeth were selected rather than resin blocks with canals, as they lack dentinal tubules and differ in hardness from that of natural teeth. The singlerooted teeth with single canals were selected, for the reason, that variations in the root canals impedes the cleaning of all root canal spaces and may cause error in the results. Eskandarinejhad $\mathrm{M}$ et al [10] also supported the use of single-rooted teeth with single canals for the study purpose.

Enterococcus faecalis was the test organism in this study as it has a major role in development of persistent periradicular lesions after root canal treatment with a prevalence ranging from $30-90 \%$, has the ability to grow in the presence or absence of oxygen, penetrate deep into dentinal tubules and survive adverse environmental conditions such as extreme alkaline $\mathrm{pH}$, high temperatures and scarce nutrition. It is the most resistant species among intracanal bacteria and in turn, has a direct effect on the outcome of root canal treatment. The pre-instrumentation samples were taken by introducing the \# 15 sterile paper points into the canal for 1 minute.

Hand K-Files were used as a reference for comparison as it is the most widely used instrumentation technique by many dentists.

The apical preparation was standardized to \# 30 for instrumentation systems because various studies have confirmed that the apical size of an instrumented canal is an important parameter in effective bacterial load reduction.

As the present study focuses on comparison of mechanical action of different file systems in intracanal bacterial population reduction, no antimicrobial irrigant was used. Chemical disinfectant could interfere with the role of an individual instrument in its microbial elimination ability from the root canal. E. faecalis can grow in $6.5 \%$ saline solution, so $0.9 \%$ saline solution, which has no antibacterial action, was employed.

The results indicate that the most effective instrumentation technique in eliminating Enterococcus faecalis from the root canal was ProTaper Next system in comparison to OneShape Apical and Hand K-File. This may be attributed to its progressively tapered file having offset rectangular crosssectional design, which generates a sinusoidal wave of motion during rotation termed as a "swaggering effect". Thus, it engages dentin on bigger circumference than its own size. Consequently, it can load and eliminate more debris with less chance of lateral compaction, compared to a similar-sized instrument with a symmetrical mass and axis of rotation. Furthermore, the taper of its final file, X3, is greater (i. e. 0.07) than the rest of the file systems used, which results in more dentin removal, and thus eliminates more bacteria. Aydın C et al [11] also found that root canals instrumented with greater taper files may contain fewer bacteria than those instrumented with smaller taper files.

OneShape Apical, a single file rotary system, showed superior efficiency in reducing bacterial population from the root canals when compared with manual Hand K-Files. It could be due to the variable cutting edge design of the file and greater taper $(6 \%)$ as compared to the Hand K-File. Vossoghi M et al [12] also showed that OneShape Apical efficiently reduce the bacterial population within the root canals.

The results of this study are in agreement with the observations of Karatas E et al [13] who found that ProTaper Next and OneShape systems were significantly effective in reducing E. faecalis within the root canals $(\mathrm{P}<.001)$. Nabeshima C K et al [14] reported that OneShape (96.5\%) resulted in significantly more bacterial reduction when compared to Hand K-File (92.7\%). Demiryurek E O et al [15] also reported that rotary instruments were more effective than hand-operated $\mathrm{Ni}-\mathrm{Ti}$ instruments in elimination of bacterial load within the root canals.

The observations revealed that ProTaper Next had significantly better efficacy in mechanical reduction of bacteria from root canal system than OneShape Apical and Hand K-File with no significant difference between OneShape Apical and ProTaper Next. However, all three instrumentation techniques were significantly effective in elimination of bacterial population. The results obtained by scanning electron microscopic evaluation were consistent with the microbiological findings. 


\section{Conclusion}

The observations above showed that all instrumentation techniques appreciably reduce the bacterial count in the root canals. When the observations above were compared, the greatest percentage reduction was found in Group $\mathrm{C}$ (ProTaper Next). But there is a dearth of literature comparing the biological efficacy of root canal instrumentation by these rotary files and conventional hand K-files. Therefore, the present study was undertaken to evaluate the efficacy of the newly introduced multiple-file system ProTaper Next and single-file system OneShape versus manual instrumentation on the reduction of $\mathrm{E}$. faecalis count in the root canal by using microbiological and SEM evaluation. The results of the present study revealed, that the mean percentage reduction of E. faecalis after instrumentation in Group A (Hand K-File) was $95.51 \%$, Group B (OneShape Apical) $97.74 \%$ and Group C (ProTaper Next) $98.13 \%$. The observations above showed that all instrumentation techniques appreciably reduce the bacterial count in the root canals. When the observations above were compared, the greatest percentage reduction was found in Group C (ProTaper Next) followed by Group B (OneShape Apical) and Group A (Hand K-File). On the basis of the observations from photomicrographs it was found that the mean of SEM scores for bacteria obtained at $1 \mathrm{~mm}$ and $3 \mathrm{~mm}$ level in Group A (Hand K-File) was $2.47 \& 1.93$; in Group B (OneShape Apical) was 1.87 \& 1.47; in Group C (ProTaper Next) was $1.40 \& 1.27$, respectively. The mean scores for bacteria were least for ProTaper Next followed by OneShape and Hand K-File at both $1 \mathrm{~mm}$ and $3 \mathrm{~mm}$ levels. Under the conditions of present study, it may be concluded that both microbiologically and scanning electron microscopically the most effective instrumentation technique in eliminating E. faecalis from the root canal was ProTaper Next system. Thus, ProTaper Next, a multiple-file system, made from M-wire technology, used in continuous rotation, having progressively tapered file design and offset rectangular cross-section may be recommended as a potential instrumentation technique for biomechanical preparation of the root canals. However, before any definite conclusion can be drawn, clinical evaluation with larger number of samples and more extensive research with a definitive data distribution should be done to evaluate the three instrumentation techniques in future.

\section{References}

[1] Pinheiro S L, Pessoa C, Silva J N, Gonçalves R O, Duarte D A, Bueno C E S. Comparative Analysis of Protaper and Waveone Systems to Reduce Enterococcus Faecalis from Root Canal System in Primary Molars -An in Vitro Study. J Clin Pediatr Dent 2016; 40: 124-128.

[2] Bystrom A, Sundqvist G. Bacteriologic evaluation of the efficacy of mechanical instrumentation in endodontic therapy. Scand J Dent Res 1981; 89: 321-328.
[3] Foschi F, Nucci C, Montebugnoli L. SEM evaluation of canal wall dentin following use of Mtwo and ProTaper NiTi rotary instruments. Int Endod J 2004; 37: 832-839.

[4] Burklein S, Benten S, Schafer E. Quantitative evaluation of apically extruded debris with different single-file systems: Reciproc, F360 and OneShape versus Mtwo. Int Endod J 2014; 47: 405-409.

[5] Mittal R, Singla M G, Garg A, Dhawan A. A Comparison of Apical Bacterial Extrusion in Manual, ProTaper Rotary, and One Shape Rotary Instrumentation Techniques. J Endod 2015; 41: 2040-2044.

[6] Chandrasekhar P, Shetty R U, Adlakha T, Shende S, Podar R. A comparison of two NiTi rotary systems, ProTaper Next and Silk for root canal cleaning ability (An in vitro study). Ind J Conserv Endod 2016; 1: 22-24.

[7] Varghese N O, Pillai R, Sujathen U, Sainudeen S, Antony A, Paul S. Resistance to torsional failure and cyclic fatigue resistance of ProTaper Next, WaveOne, and Mtwo files in continuous and reciprocating motion: An in vitro study. J Conserv Dent 2016; 19: 225-230.

[8] Hartroth, B, Seyfahrt I, Conrads G. Sampling of perìodontal pathogens by paper points: evaluation of basic parameters. Oral Microbiology and Immunology 1999; 14: 326-330.

[9] Paranjpe A, Gregorio C, Gonzalez A M, Gomez A, Herzog D S, Pina A A, MS, Cohenca N. Efficacy of the Self-Adjusting File System on Cleaning and Shaping Oval Canals: A Microbiological and Microscopic Evaluation. J Endod 2012; 38: 226-231.

[10] Eskandarinezhad M, Sadrhaghighi1 H, Rahmani M, Majd N M, Sadighi A. Comparison of two mechanical instrumentation techniques in reducing root canal bacterial population. Afr $\mathrm{J}$ Microbiol Res 2012; 6: 3635-3638.

[11] Aydin C, Tunca Y M, Senses Z, Baysallar M, Kayaoglu G, Orstavik D. Bacterial reduction by extensive versus conservative root canal instrumentation in vitro. Acta Odontol Scand 2007; 65: 167-170.

[12] Vossoghi M, Vossoghi M, Shahriari S, Faramarzi F, Mashouf R Y, Farhadian M. Efficacy of a Novel Rotary System in Reduction of Intracanal Bacteria: An in Vitro Study. Iran Endod J 2016; 11: 219-222.

[13] Karatas E, Gultekin E, Arslan H, Kirici D O, Alsancak M, Topcu M C. Evaluation of instrumentation systems in reducing $\mathrm{E}$. faecalis from root canals: TF adaptive and ProTaper next versus single file systems. Int $\mathrm{J}$ Artif Organs. 2015; 38: 161-164.

[14] Nabeshima C K, Caballero-Flores H, Cai S, Aranguren J, Britto M L B, Machado M E L. Bacterial Removal Promoted by 2 Single-file Systems: Wave One and One Shape. J Endod 2014; 40: 1995-1998.

[15] Demiryurek E O, Kalyoncuoglu E, Duran E, Coban A Y, Cayc $Y$ T. Efficacy of different instrumentation techniques on reducing Enterococcus faecalis infection in experimentally infected root canals. J Dent Sci 2014; 9: 23-28. 